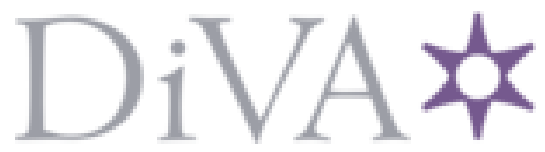

http://www.diva-portal.org

This is the published version of a chapter published in Multilingual Learning and Language Supportive Pedagogies in Sub-Saharan Africa.

Citation for the original published chapter:

Deutschmann, M., Zelime, J. (2021)

Researching Kreol Seselwa and its role in education in the pursuit of educational equity in the Seychelles

In: Elizabeth J. Erling, John Clegg, Casmir M. Rubagumya and Colin Reilly (ed.), Multilingual Learning and Language Supportive Pedagogies in Sub-Saharan Africa (pp. 61-78). on and New York: Taylor \& Francis Group https://doi.org/DOI: 10.4324/9781003028383-4

N.B. When citing this work, cite the original published chapter.

Permanent link to this version:

http://urn.kb.se/resolve?urn=urn:nbn:se:oru:diva-96133 


\section{Multilingual Learning and Language Supportive Pedagogies in Sub-Saharan Africa}

\section{Edited by}

Elizabeth J. Erling, John Clegg,

Casmir M. Rubagumya and

\section{Colin Reilly}

First published 2022

ISBN: 978-0-367-46353-3 (hbk)

ISBN: 978-0-367-67752-7 (pbk)

ISBN: 978-1-003-02838-3 (ebk)

3 Researching Kreol Seselwa and its role in education in the pursuit of educational equity in the Seychelles

Mats Deutschmann and Justin Zelime

CC BY-NC-ND 4.0

DOI: $10.4324 / 9781003028383-4$

The funder for this chapter is Örebro University, Sweden. 


\title{
3 Researching Kreol Seselwa and its role in education in the pursuit of educational equity in the Seychelles
}

\author{
Mats Deutschmann and Justin Zelime
}

\section{Introduction}

As the smallest and least populated country in Africa, Seychelles offers an accessible context for research into matters regarding language-in-education policies. Its small size allows depth of insight into the challenges faced by many nations in Sub-Saharan Africa (SSA). Although unique in many ways, the Seychelles shares several of the central language challenges common to the postcolonial conditions of the region. As most nations in the region, the Seychelles inherited a school system based on that of former colonial powers (Britain and France), and with this also a mindset which sees the colonial languages as the given carriers of knowledge. In spite of concerted efforts to raise the status and role of the first language ${ }^{1}$ (hereafter L1), Kreol Seselwa (hereafter KS), in education after independence, English remains the primary language of instruction (hereafter LoI) from primary three onwards, and secondary education is largely steered by the curriculum dictated by the structures of the British International General Certificate of Secondary Education (IGCSE). Good knowledge of English is thus a primary deciding success factor for all students in the system, something which also affects educational equity in various ways.

The Seychelles stands out as regards educational in/equity in SSA. On the one hand, it scores very highly on literacy ratings with literacy rates over $90 \%$, and truly has free education for all. Schools are relatively well funded. On the other hand, there is a lot of inequity in the system, e.g. the Seychelles had the largest withinschool variation in reading achievements among the 14 investigated nations included under the Southern and Eastern Africa Consortium for Monitoring Educational Quality (SACMEQ). Here the factor of whether English is spoken at home or not (a clear class marker in the Seychelles) and gender differences are particularly striking, something which indicates "huge inequity between pupils" (Hungi \& Thuku, 2010, p. 92). Arguably, this is a consequence of the languagein-education situation in the Seychelles.

Like many countries in SSA, the Seychelles has adopted an early-exit transitional bilingual (or partly trilingual) model of education, where all subjects except 
English, French and Mathematics are taught in the Ll (KS) for the first two years of education. KS is then replaced completely, and quite abruptly, by English, resulting in a model which in practical terms is more or less monolingual. This sudden change of the language situation in the classroom has serious implications for the learner, and as Clegg and Simpson (2016) point out, learning is lost in the absence of carefully planned and supported transition (see also Heugh et al., 2007). Not only is there a risk that students have difficulties in understanding the teacher, but they may also experience difficulties in communicating their own knowledge and understanding in a language that they are not entirely familiar with. As Clegg (2005, p. 42) puts it: "if we assess children in a second language it may not tell us what they know". Current policies also affect the content of curricula. English as a LoI means that many of the learning materials used in school are produced elsewhere, and the "local context" is often overlooked. In addition, since the current system follows the IGCSE curriculum in the final grades, the local context is of secondary importance. Overall, current policies have negative implications for the status of the $\mathrm{Ll}$, and by extension local identity and selfesteem. While the above description could fit many SSA contexts, Seychelles is unique by its small size. Not only can problems be investigated systematically, but given the will, changes can also be implemented with relative ease. Informing such moves in the Seychelles is one of our ambitions.

This chapter addresses two major questions related to the above. Based on five studies carried out between 2015 and 2018, we examine the consequences of the current language policies for young learners in the Seychelles. Second, we address the question of why a nation where the vast majority of the school population have the same mother tongue (KS) should adhere to strict L2 LoI policies. In our final discussion, we will point to potential alternatives to the current policy.

The evidence put forward in this chapter comes mainly, but not exclusively, from five studies of various aspects of the Seychelles education system that we have conducted which examine:

1. current language-in-education policy documents (Zelime \& Deutschmann, 2016)

2. students' attitudes towards the languages used in education (Deutschmann \& Zelime, 2015)

3. teacher attitudes and practices regarding LoI (Zelime \& Deutschmann, 2018)

4. how language of assessment affects student performance in the subject of Social Studies (Zelime, Deutschmann \& Rijlaarsdam, 2018)

5. how choice of language affects students' ability to write about local contexts (Zelime \& Deutschmann, 2019).

In addition, we provide an historical background on the Seychelles language situation, aiming to give an informed evaluation of how the current system affects the learning situation of young Seychellois. We relate our findings to Spolsky's Theory of Language Policy $(2004,2019)$, in order to explore the question of why the current system is the way it is. Finally, we propose productive pathways 
forward by suggesting potential adaptations of the current system which take the many different factors and interests that may affect such processes into account and by striking a balance between them.

\section{Theoretical framework}

Spolsky (2004) asserts that there are several coexisting, but often conflicting, factors that motivate a country's language-in-education policies. These are divided into three main domains in his framework: language practices, language beliefs and "any specific efforts to modify or influence that practice by any kind of language intervention, planning or management” (Spolsky, 2004, p. 5). He argues that the language policy of any independent nation state will reveal the complex interplay of these "interdependent but often conflicting factors" (2004, p. 133). Spolsky (2019, p. 326) maintains that this is a complex and chaotic non-hierarchical system", which more traditional bottom-up/top-down models are unable to capture. Instead, each level within a system can have its own logic, and each domain can influence and be influenced by all the other domains. According to Shohamy (2008, p. 364), Spolsky's (2004) framework:

introduces a broader concept of language policy, one that incorporates ideology, ecology and management, arguing for a complex relationship among these components and thus providing a fuller and more comprehensive understanding of what language policy really is.

Spolsky's framework puts focus on the interplay between different aspects such as national ideology, the role of English as a global language, a nation's sociolinguistic situation, political interests, economic interests, language beliefs as shaped by history, as well as micro level factors such as language practice at home and elsewhere outside school. The Seychelles is particularly interesting to research from this perspective. As a very small nation with a population of less than 100,000 inhabitants, various "actors" and their role in shaping current policies can quite accurately be identified. "Actors", in this context, may refer to human individuals, but also other entities such as global politics, new technological developments and economic interests.

\section{Background: the Seychelles}

The Seychelles are situated four degrees south of the equator in the western Indian Ocean. The islands have no indigenous population and are inhabited by people with a creole mix of African, European and Asian descent. The pillar of the economy is tourism, closely followed by the fisheries industry. The Seychelles boasts the highest nominal per capita GDP in Africa, and it has a high Human Development Index (see United Nations Development Programme, 2019). However, poverty remains a widespread problem due to the high level of economic inequality (World Bank, 2020). 
The Seychelles education system is based on a comprehensive policy of education for all (Ministry of Education, 2004). It consists of 11 years of compulsory schooling (generally from the age of 6 to 16), preceded by two years of early childhood education (generally ages three-and-a-half to five-and-a-half) which are not compulsory, but which most children attend (Ministry of Education, $2000 ; 2004)$. The system is closely steered and monitored by the Ministry of Education, and highly exam oriented. Final exams in the compulsory system take place in secondary Grade 5, when the most promising students sit their IGCSEs exams, given by Cambridge International. In addition to state schools, there are four private schools on the islands, three of which conduct their teaching entirely in English and one which is based on the French system.

\section{History}

In the eighteenth century, when the islands were first colonized by the French, the practice of "deculturation" (Chaudeson, 2001, p. 91) meant that African languages and cultural expressions were forbidden. As a consequence, a new language, KS, emerged within a generation or two as the initial simple French pidgin developed into the mother tongue of the majority through the process of creolization (see Bickerton, 1977 for further details). The Seychelles became a British colony in 1815. However, French kept its role in religious practice, high culture and in education until the 1940s, when the church-owned schools were replaced by more formal and organized state schools based on the English system. Now English also became the sole LoI (Fleischmann 2008, p. 74). During the entire colonial period, KS remained a low status language, confined to informal discourse and completely banned from schools. Students were punished for using KS in school and such punishments could include "writing lines", formal rituals designed to bring ridicule to the "offender", and even corporal punishment (Fleischmann, 2008, p. 141).

The language situation in the Seychelles during this historical period is a direct reflection of the pre-independence power structures on the islands: the British were the formal administrative rulers, while the francophone elite still retained considerable economic power and influence. A prerequisite for access to positions of power (within the fields of administration, law, religion and education, for example) among the general Creole-speaking population (94\% according to Moumou (2004, p. 46)) was a mastery of English, and to a lesser extent French. In spite of this, KS survived as the everyday language of the majority, regardless of class or race, arguably a result of its role in signalling the Creole identity that distinguished the local population from the colonial cultures.

\section{Post-independence era: the recognition of KS}

With independence in 1976, and the subsequent left-wing coup d'état in 1977, the status of KS improved, and it began its journey towards becoming an official language with a role in politics, culture and education. The establishment of KS 
as an official national language played a key role in the nation-building process. It was a way of marking a break with the colonial past and the establishment of a new cultural and linguistic autonomous identity (Ivanov, Deutschmann \& Enever, 2015). However, the elevation of KS to a formal language was not given, even among its speakers. During the late 1970s and early 1980s, there were intense status and corpus planning efforts (Baldauf \& Kaplan, 2005) to raise the status of KS (see Fleischmann, 2008, pp. 58-67 for further details of this process). Not only did this process involve the formalization of orthography, grammar and lexicon, but also included several translations of key works of literature into KS, and other efforts in the cultural sector. Most importantly, KS was given a role in education, both as LoI and as an academic subject. The implementation of KS in education also meant that learning materials had to be produced, and above all, teachers had to be trained for the task of teaching KS. In spite of these challenges, the Seychelles became the first Creole-speaking nation in the world to implement a creole language as a LoI in education in January 1982 (Siegel, 2005).

KS was initially introduced as LoI from primary Grade 1 to Grade 4 and was also taught as a separate subject until primary Grade 6. In addition, KS became the sole LoI throughout the compulsory grades of schooling in the subjects of Social Education, Physical Education, the Creative Arts and Religion. KS thus formed part of a trilingual policy where English remained the LoI in "academic" subjects after primary Grade 4, where KS was the LoI up to primary Grade 4 but had a primary role in more practical subjects, and where French was taught as a foreign language from primary Grade 1 (Campling, Confiance \& Purvis, 2011; Purvis, 2004). Instructing young children in their mother tongue had highly positive effects. Comparisons of the last classes to be taught in English and the first classes taught under the new system showed that the latter outscored the former in almost every subject, including French and the sciences. Interestingly, the children who had been taught in KS also performed as well in the subject of English as the previous groups, who had been taught exclusively in English (Bickerton, 1990, p. 48). In addition, literacy rates went up radically (Campling, Confiance \& Purvis, 2011, p. 51). Note that these findings were based on data from the entire primary Grade 6 cohorts in the country, and therefore have important implications for the SSA region as a whole.

\section{Recent setbacks and challenges}

As the previous section illustrates, KS was given a lot of attention and corpus planning in the Seychelles, a state of affairs somewhat unique in SSA contexts. Despite this, KS's role in education and elsewhere has suffered serious setbacks over the last decades. After concerns were raised by the Language Policy Review Committee report in 1994, a study based on interviews with teachers, parents and the general public, KS's role as LoI was reduced to primary Grades 1 and 2 in 1996. There were several motivations for this: policymakers argued that with increased exposure to English in popular media (television for example), children were better equipped to 
handle an earlier switch to English as LoI. Further, teachers reported finding the transition from one LoI to another challenging, claiming that they had to "re-teach" children basic concepts after primary Grade 4 as they failed to grasp these in English. Lack of resources was also seen as another primary obstacle for further promoting KS in schools. Producing textbooks to cover all the subjects on all levels was perceived as not feasible in a country with a population of less than 100,000 , and it was also challenging to meet the demand for teachers trained in KS (Ivanov et al., 2015). Although legitimate, we would argue that many of the points of critique raised in the 1994 report could have been overcome had there been a will. There were however other, more ideologically oriented factors, that probably contributed to the weakened role of KS in education.

The changed status given to KS in education, and elsewhere, is also likely to have been affected by the political changes that took place in the republic during the early 1990s. In 1993, the so-called "Third Republic" was declared, and the Seychelles became a multi-party democracy with free elections. From this time onward, the Seychelles also gradually moved from a relatively centrally state controlled planned economy (highly dependent on aid from the former Soviet Union and its allies) to a more open liberal economy, where "solidifying old and soliciting new ties with some of the world's most influential powers abroad" became increasingly important in the bid to join the global economic community (Laversuch, 2008, p. 377). According to Laversuch, language policies propagating the use of English and French at the expense of KS were largely economically motivated in order to "assist the country in gaining a foothold in other foreign markets where English and/or French are used as the primary/exclusive language(s) of government and business" $(2008$, p. 378). It is also feasible that the ruling party wanted to dissociate itself with some of the more radical reforms that had taken place after it seized power in 1977 in order to appeal to a greater proportion of the general electorate; the introduction of KS in education was considered by many to be one such radical reform.

Whatever the reasons, from 1996 to date, the role of KS in education has become increasingly limited. It is now only used as LoI during primary Grades 1 and 2 and ceases to be a subject at school after primary Grade 6. Many argue that it should be abandoned altogether as LoI, and in fact this has already happened in the subject of Mathematics, which is now taught entirely in English from primary one onwards. Another issue of concern is the role of KS as "language of support" in the current system, i.e. a language into which teachers can switch for the purpose of increasing understanding of concepts. Although it is clearly stated in the National Curriculum Framework (NCF) (Ministry of Education, 2013) that KS can be used in this capacity throughout the education system, there are indications that this is becoming less and less acceptable (see Zelime \& Deutschmann, 2016).

\section{Current studies}

The studies on which we draw our evidence in this chapter are part of a greater project, where the ambition has been to survey the state of the current 
language-in-education situation in the Seychelles, and how things have changed since the 1996 reforms. In this chapter, however, our focus lies on an analysis of the impact of the specific findings from the studies that relate to how language policies, at various policy levels (from management to practice), affect the role of KS in the system and educational equity (or lack thereof). In order to show how various aspects (expressed language policies, belief systems and practice) contribute to the current language-in-education situation in the Seychelles, we have used Spolsky's framework of language practices, language, beliefs and values, and language planning and/or management. This choice of method is motivated in order to provide the "bigger picture", and an overall understanding of the language-in-education context of a country which is relatively unfamiliar to most readers. We refer those interested in more specific details to the original articles.

The main aim of Study One (Zelime \& Deutschmann, 2016) was to investigate the intentions of the declared trilingual language-in-education policy in the Seychelles NCF, and how overarching ideologies expressed in this document were (or were not) translated into directions for specific implementation and intended practice in other steering documents, and in the three-language subject curricula, namely KS, English and French. Our findings revealed that there were large discrepancies between the overarching principles expressed in the NCF and those evident in the specific subject curricula. In the NCF all three national languages are given central roles and equal status, and if anything, the role of KS is highlighted. The NCF clearly states that any of the three languages can be used as "support languages" throughout the system in the pursuit of providing quality, goal oriented, individualized and student-centred education for "all", regardless of social class or gender. There is a strong emphasis on literacy in all the three languages (KS, English and French). A weakness in the document, however, is that there are very few practical guidelines about the specific role of each language in teaching and examination.

While the status of the three languages is equal in the NCF, clear differences in the power and functions of the languages emerge in the subject curricula. From the descriptions, it is evident that the role of KS is peripheral and mainly serves as a transition language, which is used to develop basic learning skills and thereby help young children to enter the more complex cognitive universe of the ex-colonial languages. In contrast, English is described as instrumental for knowledge acquirement and academic success. The peripheral role of KS is also evident from the time allocated to this subject in the curriculum. From primary Grade 3 to Grade 6 KS is allocated five weekly slots in the timetable, and it ceases to be a school subject after primary Grade 6. In contrast, English is allocated seven weekly slots and is also the LoI. Similarly, while the use of KS as support language is advocated in the NCF, this is actively discouraged in practical guidelines to teachers produced by the Ministry of Education as evidenced from the following quote:

[...] the prescribed medium of instruction has to be respected by teachers and greater emphasis has to be placed on more effective curriculum 
implementation. This is due to the fact that $80 \%$ of inspectorate reports revealed a high degree of code-mixing during the delivery of lessons.

(Education Sector Medium-Term Strategic Plan, Ministry of Education, 2014, p. 47)

The practice of using KS as support language (which presupposes "code-mixing"), a central principle in the NCF, is questioned and positioned as deficit practice.

Study Two (Deutschmann \& Zelime, 2015) explored language attitudes of learners regarding the three school language subjects, KS, English and French among students in primary and secondary schools in the Seychelles. These attitudes were then correlated with students' performance in these subjects in the primary six national assessments. Questionnaires were distributed to approximately 400 learners, from primary Grade 1 to secondary Grade 3, to capture their attitudes towards the four basic language skills (reading, writing, listening and speaking) in the three languages.

The results clearly showed that students of all ages were very positive towards KS. These positive attitudes were particularly noticeable in the primary Grades where KS was favoured over English and French in all four literacy skill domains. These attitudes were also mirrored in the primary six national assessments, where KS was the subject students performed best in. There was, however, a clear change in attitudes towards writing and reading (but not listening or speaking) in KS once students entered the secondary level. Secondary students were significantly more negative towards reading and writing in KS. The more negative attitudes towards KS as a written language seem to be a reflection of KS ceasing to be an academic subject after primary Grade 6. Further, negative attitudes towards English were particularly evident among primary school boys. These attitudes were also mirrored in their primary six exam results, where girls massively outscored boys in English.

Study Three (Zelime \& Deutschmann, 2018) investigated the language beliefs, attitudes and classroom practices of primary school teachers. Findings were based on questionnaire answers from 142 teachers in 22 primary schools (almost all primary schools in the Seychelles), coupled with classroom observations and teacher interviews. Findings revealed that while the vast majority $(98 \%)$ of teachers used KS for everyday oral communication, they were, on the whole, quite negative to its role in education. None of the respondents were positive to its potential use as LoI from Grade 3 onwards, and a striking 96.5\% of the respondents would have liked to see English introduced as LoI even earlier in system (even at preschool level) (p. 139). Teachers were thus far more positive towards English as a LoI. Even in very locally contextualized subjects such as Social Studies, very few thought that students would perform better if taught in KS. Further, a substantial number of the teachers believed that English-only practice should be used when teaching (i.e. KS should not be used as support language). A clear majority of the teachers thought the advantages of teaching in English outweighed the disadvantages in the current system. KS was generally viewed as a less prestigious language than English, in particular in professional contexts. For example, very 
few of the teachers were of the opinion that a good knowledge of KS was advantageous on the job market.

Results from the classroom observations of six primary Grade 6 school teachers supported the findings from the questionnaires. KS was used very frequently by the majority of learners, but hardly ever by the teachers. For instance, KS was used extensively by students during group work, when the teacher was out of earshot. Further, many learners answered questions that the teachers posed to them in English using KS, for example, when struggling to express themselves in English. Overall, teachers did not encourage this and responded to such utterances in English, and also insisted that students use English. This practice also meant that those students who were reasonably proficient in English were given disproportionate amounts of floor space. In some lessons, for example, one or two learners did almost all the talking because they were clearly proficient in oral English. The insistence on English-only communication also meant that there was very little exploratory talk (Barnes, 1976; 2008), i.e. less formal and more dialogic communication where the teacher and learners interact to explore new concepts. This was partly due to the fact that in spite of their insistence on English, many of the teachers were themselves sometimes struggling to express themselves in this language. As a result, over $90 \%$ of the teacher-student discourse was made up of teacher-centred pre-prepared plenary talk (Hardman, 2008), or short question response-type dialogues, where the focus lay on transmission rather than construction of knowledge. In our interviews with teachers, it was clear that they recognized that many learners had difficulties in understanding what was being taught and needed support. However, it was also clear that the teachers lacked strategies to deal with this problem, something which some teachers reluctantly acknowledged.

Study Four (Zelime, Deutschmann \& Rijlaarsdam, 2018) explored how the language of assessment affected students' opportunities to communicate their knowledge, and the impact of this on their academic performance. A withingroups experimental design was implemented, and 151 primary Grade 6 students (11 to 12 years) from three different schools wrote a short test in both KS and English, in a counterbalanced design. The theme of the test was fishing, a topic in the Social Studies curriculum which is based mostly on local contextual knowledge, and which is taught in English. The tests were marked by three independent graders for content in both languages. In our analysis of results, we also compared results between "high-performing" students and "low-performing" students, as defined by the local class streaming practice (upper and lower streams where the former are defined as high performers).

The main finding showed that the participants scored significantly higher in this specific Social Studies test when they received instructions and were allowed to write in KS as opposed to English. This effect constituted approximately a $13 \%$ improvement based on the total score. In this particular study, we could not show that there were any significant differences in the magnitude of the difference between English and KS test scores among upper- and lower-stream students. Thus, the study implies that the use of English as test language leads to 
a general performance loss affecting all students, irrespective of class level (upperand lower-stream). Note here, however, that in an exam-oriented system with distinct pass and fail levels, a 13\% loss of performance will be more serious for a weaker student than a high performer.

Finally, Study Five (Zelime \& Deutschmann, 2019) investigated the extent to which the choice of language was a factor influencing primary Grade 6 students' writing and their opportunities to incorporate their own knowledge, person, experiences and world views in their school knowledge production. The evidence was based on findings from the corpus of 308 written texts, produced in Study Four above. In our analysis, we included text length and compared aspects of the ideational and interpersonal dimensions (see Halliday, 1994) in students' texts written in L2 (English) and Ll (KS). The study investigated the degree of code switching, i.e. the interpolation of KS words/phrases into the English text and vice versa, and the use of first person pronouns (since we wanted to investigate identification with the topic) in the two sub-corpora, and how differences could be accounted for qualitatively. We also compared texts of high-performing and low-performing students with respect to the above.

The results showed that the texts written in KS were longer than those written in English. Further, there were far more examples of code switching in the English texts, and this was particularly the case for texts written by the "weaker" lower-stream students. To try to deal with language shortcomings, lower stream students drew on KS to explain what they meant. The Kreol words that appeared in the English texts typically described local objects and phenomena (fish names, local fishing methods, places and food). Fish names were particularly common in the code-switching data, and it is evident from the results that children in the Seychelles possess a very rich vocabulary to describe this semantic domain in KS. This was not the case in English. The use of English words in the KS texts was relatively rare, and restricted to the phenomena that children learn about in school, for example words such a fish factory, cannery, purse seiners and foreign exchange. Finally, the use of the first person pronouns in the KS texts was almost twice as frequent as in the English texts. The difference in frequency of usage of these pronouns in English texts and KS texts was greatest among lower-stream students. First person pronouns primarily referred to aspects related to local and national identity: our country, our economy, etc. In addition, and especially in the KS texts, personal pronouns were also often used to signal inclusiveness with the activities described: “nou servi kazye pou attrap pwason; nou lapes” etc. (we use fish traps to catch fish, we fish, etc.). These pronouns were often replaced by they in the English texts (the fishermen) signalling a greater distance and less identification with the topic.

In summary, the intentions of the NCF are reasonably clearly stated: in the pursuit of educational equity, all languages have an equal role to ensure individualized education which takes the prerequisites of each learner into account. As the results from the five studies taken together show, however, the intentions of the NCF do not translate well into practice. One important factor in this is arguably teacher attitudes, which are generally very negative towards the role of KS in the 
system, and which also seems to be highly influential when it comes to practical implementations of policy intentions. The overall result is a system where the role of the mother tongue in education is marginalized, and this has negative effects on the learning situation of all learners, but particularly for those who have limited access to English.

\section{Discussion}

In the following, we explore why policies and classroom practices differ so much and what happens to the NCF's principles in the stages between the planning and implementation. To do so, we draw on Spolsky's framework, which suggests that such differences occur when there are conflicting interests at work. We identify some of the conflicting interests, ideologies and practices working in the Seychelles system regarding the role of KS and, ultimately, educational equity. Figure 3.1 gives insight into some of these factors, including local politics, historical factors, global factors, economic factors, foreign language interests and practical circumstances in the field. We then discuss potential models of change to counteract current trends (i.e. the belief systems and practice models indicated by dotted lines in Figure 3.1 below).

\section{Local and outside influences}

Laversuch (2008) points to the forces of economics and globalization in the diminishing role of KS in the Seychelles education system, and this is partly confirmed through interviews with senior Curriculum Officers (see Ivanov, Deutschmann \& Enever, 2015). With the increased importance of tourism, combined with a more global context afforded through social media and increased

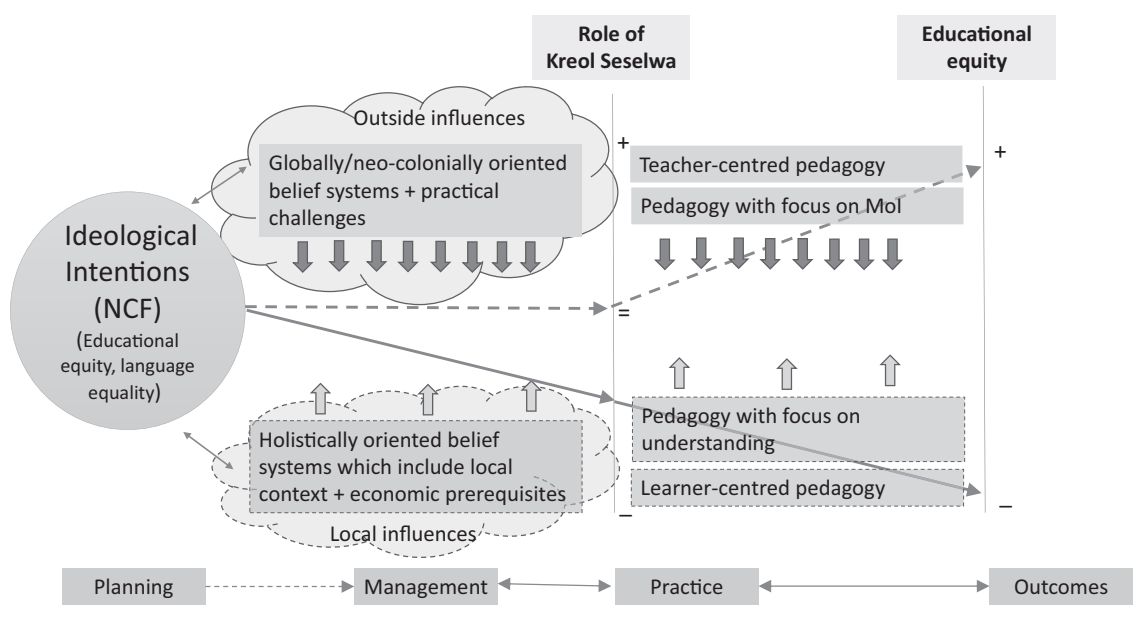

Figure 3.1 Influences affecting the intentions of the National Curriculum Framework. 
travel, English has become increasingly important. Study Two evidences that pragmatic considerations such as employability are key motivating factors for teachers' negative perceptions of the role of KS in education (see also Fleischmann, 2008). Teachers cannot see the point of propagating a language which is only locally relevant.

This negative view of KS is also strengthened by historical factors. According to Mahoune (2000), a "colonial hangover" makes it hard for Creoles to accept their own language as one equal to others. English is still the language of administration in the Seychelles, and although KS was given strong political backing in the 1980s and early 1990s, a majority of the population still associate success and development with English (and to a lesser degree French). Many of today's decision makers owe their success to the old colonial and/or private school systems where KS had/has no role. Further, among this social class, English or Frenchonly private schools are becoming an increasingly popular alternative for their children's education, and this adds to the myth that English and/or French is a recipe for academic success. Such forces can essentially be viewed as neocolonial (see Figure 3.1 above), reinventing old colonial ideals, and/or examples of elite closure, i.e. when "the elite successfully employ official language policies $[\ldots]$ to limit access of nonelite groups to political position and socioeconomic advancement" (Myers-Scotton, 1993, p. 149).

Given these circumstances, KS's role in education is politically sensitive, and the current government are well aware of the delicate balancing act the language issue in education involves. Giving too much emphasis to English as LoI would potentially alienate parts of the electorate, while the reverse risks irritating others. Avoiding specific directives regarding the role of specific languages in the NCF is arguably a way of playing it safe by committing to a trilingual language policy in principle, without specifying the practicalities. Unfortunately, this strategy comes at the expense of leaving teachers and students without clear guiding principles for language practice at school. This opens up possibilities for variation in practical implementation, driven by different ideologies. In this process the teachers and their ideologies are key factors.

As evidenced from our studies, teachers are generally quite negative towards KS in education (see also Fleischmann, 2008). Teachers are also very influential: for example, the 1996 reforms reducing the role of KS in education were largely motivated by teacher opinions. Further, since the Ministry of Education is largely made up of former teachers, teacher ideologies are largely reflected in their practice-oriented management policies. Moreover, the Seychelles is a small country, and many of the public servants in the Ministry are former colleagues of the teachers they are monitoring. Teachers are, just like the rest of the population, influenced by colonial/neocolonial ideals and current global trends, but there are also other factors that contribute to teachers' negative attitudes towards KS.

The Seychelles education system is currently facing a number of challenges affecting teachers' work environment. Lack of discipline in schools has long been an issue. After a number of incidents of violence, many secondary teachers feel personally threatened. There has also been a general decline in academic 
achievement over the past 10 to 15 years, and it has become increasingly difficult to recruit new teachers to the profession. A common opinion among teachers is that there has been a general "moral decline" in the country, and that "things were better before". Many incorrectly blame progressive reforms, such as the abandonment of corporal punishment and the introduction of KS, for the current state of affairs. Further, there is a general lack of resources for aspects such as infrastructural investments and vocational training to meet current challenges. These factors have led to the system experiencing a negative spiralling effect, and quite incorrectly KS is seen as part of the problem, a situation which is probably mirrored in many SSA contexts.

\section{Language practice}

As Spolsky (2004) points out, language, beliefs and values are intrinsically interwoven with practice, and current LoI practice has highly negative pedagogic consequences. Our classroom observations show that teacher-oriented pedagogy in combination with strict English-only practice means that many learners are unable to access what is being taught. Further, as shown by Study Four, current assessment practices also mean that learners are unable to express what they know adequately. This is reflected in exam results, where a large proportion of the primary Grade 6 students fail in key subjects such as English and Maths. In addition, the exclusion of KS means that learners are denied the opportunity to express themselves and relate their everyday experiences to their school knowledge, and the local context is thus marginalized (as shown in Study Five). This is just one illustration of what Spolsky (2009) refers to as a serious gap between the L1 and the L2, where children will be convinced that their local knowledge and languages are in some way deficient and irrelevant.

Teacher-centred pedagogy coupled with an exam-oriented system, and a strict monolingual practice as regards LoI, lead to an increase of inequity in the system. As Study Two shows, individuals who understand what is being taught are given more teacher time and do relatively well, while those who cannot follow what is going on are isolated and left with little support and fail. This, we would argue, is one of the reasons for current disciplinary issues in the Seychelles schools today. Many students feel abandoned by the current system and react negatively. As Erling $(2017$, p. 388) points out, English language skills might enhance opportunities for individuals, but they also reinforce embedded inequalities and thereby do not necessarily contribute to the overall well-being of societies.

This is certainly the case in the Seychelles. While some learners manage to negotiate the system and get good enough grades to enter post-secondary education and university, and thereby secure good jobs, a larger section of learners leave school with no qualifications whatsoever. This is reflected in current labour statistics (see Seychelles National Bureau of Statistics): there is a general lack of skilled labour (particularly in tourism and construction) and the Seychelles houses approximately 22,000 expatriate workers, while unemployment remains an issue among the local population. 


\section{Potential models of change}

In any model of change, we argue that the merits of all the languages in the current system should be recognized as potential contributors to communication and understanding. In this pursuit we would argue that additive multilingual models represent a way forward. Such models recognize the use of the Ll plus official/foreign language/s as dual/multiple media of instruction to the end of school. In the additive education model, the mother tongue is never removed as a LoI, even if its role gradually may be reduced as learners become more proficient in the L2 LoI. The advantage with such models is that they encourage a high level of proficiency in the mother tongue in addition to a high level of proficiency in the official/foreign language.

There has been much research carried out in SSA that speaks for the promotion of additive models in all stages of primary, secondary and tertiary education in order to maximize the quality of education (see Wolff, 2011 and Heugh, 2011, for example). Perhaps more so than in other SSA contexts, such a system is highly feasible in the Seychelles, and there are many local factors that speak in favour of successful implementations. For example, the Seychelles is a small country and it is reasonably easy to reach all practitioners for training. Further, the Seychelles has a relatively uncomplicated language situation where KS is spoken by the vast majority. There are thus no arguments speaking in favour of favouring English as a neutralizing lingua franca in a complex ethnic situation, as is the case in many SSA countries. In addition, KS has been standardized, and formal orthography, grammar, lexicon, etc. are already in place. The biggest hurdle to changes in the current practice, as we see it, are current belief systems that resist the expanded role of $\mathrm{KS}$ in education.

In line with Spolsky, we argue that, in order to be successful, any potential future language policy has to acknowledge current language ideologies, where the beliefs of key actors like teachers are of primary importance. Consequently, we maintain that new LoI models that are based on different language ideological frameworks than current ones will not succeed unless teachers are thoroughly introduced to the thinking behind these new frameworks (in teacher training or vocational training). Models for change also have to acknowledge and respect current ideologies and practices, even when, at first sight, these may seem to be in conflict with the pursuit of educational equity.

One of the main problems in the Seychelles context is that there has been a history of setting language belief systems against each other in the interest of political pursuits. The colonial powers diminished the local language and culture in order to elevate and justify their own systems, and similarly the colonial systems and languages were discredited in post-coup d'état nationalist pursuits of the 1980s, which in turn led to a backlash after 1996. This has created a polarized situation where belief constructs are either for or against KS/English in education, and where the practitioners largely are in favour of English. This practice of equating specific languages with educational successes/failures is, we would argue, not constructive. Rather than fronting the role of a specific LoI in the 
educational system, emphasis should instead be placed on the role of communication and understanding of ideas and knowledge, regardless of language. In this pursuit, pedagogy (rather than language) needs to be the focus of attention.

It is also here that we see that major efforts need to be made in order to better inform teachers, and the general public, of the merits of multilingual education. In such efforts, focus on understanding and knowledge attainment need to be primary, and LoI secondary. For example, it is not important what language is used to teach basic mathematical concepts. What is important is that students understand them. Further, the implementation of an additive model should not be seen to threaten current assessment standards such as IGCSEs. KS should be presented as a way of helping knowledge development, while at the same time recognizing the importance of the global context. It is simply not realistic that Seychellois citizens would accept an abandonment of international systems given its small and rather isolated position.

\section{Conclusion}

In conclusion, this study of the Seychelles illustrates a general dilemma in postcolonial contexts such as SSA: in the bid to align education with international standards and content (IGCSEs for example), and to prepare for engagement in a global community, systems adopt a more or less monolingual approach. Such changes are often made easier due to language ideologies that linger on from colonial times. While such policies do in fact open up international opportunities for a limited group, they also shut the door for large sections of the population, who are not able to negotiate the linguistic hurdles. What is more, such policies also come at a cost - the inability of indigenous languages and cultures to develop and contribute to development. In reversing such tendencies, we would argue for models which emphasize pedagogy and learning as opposed to being fixated with LoI as a way forward in SSA.

In the pursuit of such models, informed research plays a critical role. Much research to date has pointed to the shortcomings of current transitional models in SSA, and how these lead to educational inequity (see for example UNICEF, 2016 for a comprehensive overview). Our own research reveals similar flaws in the Seychelles. Arguably, there has been enough research conducted for us to say that we know that language issues lie at the heart of many of the challenges facing pupils and teachers in the SSA region today. Nevertheless, systems based on former colonial languages as sole LoI persist. Radical changes seem to be politically inconceivable, something which in turn may be a result of a postcolonial mindset and so-called elite closure (Myers-Scotton, 1993). Here we would argue that research which demonstrates how indigenous African languages can play an important supportive role within current systems in order to improve learning is extremely important. Controlled intervention studies and action research with the aim to develop and test various additive language models and measure their effects on learning are essential in the pursuit of educational improvements. Such studies could give concrete evidence that there are real alternatives to current 
LoI practices that still accommodate the demands of international systems based on former colonial languages such as English and French. In short, such evidence based on research is a key component in disarming arguments against strengthening the role of indigenous languages in schools in the SSA region.

\section{Note}

1 The term first language (L1) is used in this chapter synonymously with mother tongue, and refers to the language that a person first is exposed to and acquires in early childhood because it is spoken in the family and/or is the language of the region or community where the child lives.

\section{References}

Baldauf, RB \& Kaplan, RB 2005, 'Language-in-education policy and planning', in E Hinkel (ed), Handbook of Research in Second Language Teaching and Learning, Erlbaum, Mahwah, NJ, pp. 957-970.

Barnes, D 1976, From Communication to Curriculum, Penguin Books, Harmondsworth.

Barnes, D 2008, 'Exploratory talk for learning', in N Mercer \& S Hodgkinson (eds), Exploring Talk in School: Inspired by the Work of Douglas Barnes, Sage, London, pp. 116. http://dx.doi.org/10.4135/9781446279526.nl

Bickerton, D 1990, 'Instead of the Cult of Personality', Notes on Linguistics, vol. 49, pp. 47-50.

Bickerton, D 1977, 'Pidginization and creolization: Language acquisition and language universals', in A Valdman, (ed), Pidgin and Creole Linguistics, University Press, Bloomington, IN, pp. 49-69.

Campling, L, Confiance, H \& Purvis, M 2011, Social Policies in Seychelles. Social Policies in Small States Series, Publication Section Commonwealth Secretariat, London.

Chaudeson, R 2001, Creolization of Language and Culture, Routledge, London.

Clegg, J 2005, 'Moving towards bilingual education in Africa', in H Coleman (ed), Language and Development: Africa and Beyond Proceedings of the 7th International Language and Development Conference, British Council, Addis Ababa, pp. 40-50.

Clegg, J \& Simpson, J 2016, 'Improving the effectiveness of English as a medium of instruction in sub-Saharan Africa', Comparative Education, vol. 52, pp. 359-374.

Deutschmann, M \& Zelime, J 2015, “"I used to like writing in Kreol but now I only use English": An exploratory study of language attitudes and examination performance among primary and secondary school students in the Seychelles', Island Studies, vol. 1, pp. 36-45.

Erling, EJ 2017, 'Language planning, English language education and development aid in Bangladesh', Current Issues in Language Planning, vol. 18, pp. 388-406.

Fleischmann, CT 2008, Pour Mwan Mon Lalang Maternel i Al avek Mwan PartouA Sociolinguistic Study on Attitudes towards Seychellois Creole, Peter Lang, Bern.

Halliday, M 1994, An Introduction to Functional Grammar, Edward Arnold: London.

Hardman, FC 2008, 'Teachers' use of feedback in whole-class and group-based talk', in M Neil \& H Steve (eds), Exploring Talk in Schools: Inspired by the Work of Douglas Barnes, Sage, London, p. 131.

Heugh, K 2011, 'Theory and practice - language education models in Africa: Research, design, decision-making and outcomes', in A Oane \& C Glanz (eds), Optimising 
Learning, Education and Publishing in Africa: The Language Factor - A Review and Analysis of Theory and Practice in Mother-Tongue and Bilingual Education in subSaharan Africa, UNESCO, Hamburg, pp. 105-156.

Heugh, K, Benson, C, Bogale, B \& Mekonnen, A 2007, Study on Medium of Instruction in Primary Schools in Ethiopia, Ministry of Education, Addis Ababa, Ethiopia.

Hungi, N, \& Thuku, F 2010, 'Variations in reading achievement across 14 Southern African school systems: Which factors matter?', International Review of Education, vol. 56, pp. 63-101.

Ivanov, S, Deutschmann, M \& Enever, J 2015, 'Researching language-in-education policies: Evidence from the Seychelles, Russia and the European Union', in E Lindgren \& J Enever (eds), Researching Language Teaching and Learning. Department of Language Studies, Umeå University, Umeå, pp. 85-101.

Laversuch, IM 2008, 'An unequal balance: The Seychelles' trilingual language policy', Current Issues in Language Planning, vol. 9, pp. 375-394.

Mahoune, JCP 2000, 'Seychellois creole development \& evolution', IIAS Newsletter, vol. 22 , p. 21.

Ministry of Education 2000 Education for a Learning Society-Policy Statement of the Ministry of Education, Ministry of Education, Mahé, Seychelles.

Ministry of Education 2004, Education Act-Non-Formal Early Childhood Education Centre, Ministry of Education, Mahé, Seychelles.

Ministry of Education 2013, The Seychelles National Curriculum Framework, Ministry of Education, Mahé, Seychelles.

Ministry of Education 2014, Education Sector Medium-Term Strategic Plan 2013-2017 and Beyond, Ministry of Education, Mahé, Seychelles.

Moumou, M 2004, 'Preparing our students for the future: Critical literacy in the Seychelles classrooms', English Teaching: Practice and Critique, vol. 3, pp. 46-58.

Myers-Scotton, C 1993, 'Elite closure as a powerful language strategy: The African case', International Journal of the Sociology of Language, vol. 103, pp. 149-164.

Purvis, M-T 2004, 'Education in the Seychelles: An overview', Seychelles Medical and Dental Journal, vol. 7, pp. 46-51.

Seychelles National Bureau of Statistics 2019, Economic Statistics. Victoria, Mahe, Seychelles www.nbs.gov.sc/

Shohamy, E 2008, 'Language policy and language assessment: The relationship', Current Issues in Language Planning, vol. 9, pp. 363-373.

Siegel, J 2005, 'Literacy in pidgins and creole languages', Current Issues in Language Planning, vol. 6, pp. 143-163.

Spolsky, B 2004, Language Policy, Cambridge University Press, Cambridge.

Spolsky, B 2009, Language Management, Cambridge University Press, Cambridge.

Spolsky, B 2019, 'A modified and enriched theory of language policy (and management)', Language Policy, vol. 18, pp. 323-338.

United Nations Development Programme 2019, Human Development Report: Beyond income, beyond averages, beyond today: Inequalities in human development in the 21st century, UNDP, New York http://hdr.undp.org/en/2019-report

UNICEF 2016, The Impact of Language Policy and Practice on Children's Learning: Evidence from Eastern and Southern Africa, UNICEF, Paris www.unicef. org/esaro/UNICEF(2016)LanguageandLearning-FullReport(SingleView).pdf.

Wolff, E 2011, 'Background and history - Language planning in Africa', in A Oane \& C Glanz (eds), Optimising Learning, Education and Publishing in Africa: The Language 


\section{Mats Deutschmann and Justin Zelime}

Factor - A Review and Analysis of Theory and Practice in Mother-Tongue and Bilingual Education in sub-Saharan Africa, UNESCO, Hamburg, pp. 49-100.

World Bank 2020, GINI-index (World Bank estimate). The World Bank, Washington, DC, https://data.worldbank.org/indicator/SI.POV.GINI

Zelime, J \& Deutschmann, M 2016, 'Revisiting the trilingual language-in-education policy in the Seychelles National Curriculum Framework and subject curricula: Intentions and practice', Island Studies, vol. 3, pp. 50-59.

Zelime, J \& Deutschmann, M 2018, 'Conflicting ideologies: When the ideological meets the perceived and operational - A study of primary teachers' attitudes, perceptions and practice of Seychelles Creole (Kreol Seselwa) and English as mediums of instruction in the Seychelles primary schools', in K Smith (ed), Norsk og internasjonal larerutdanningsforskning: Hvor er vi? Hvor vil vi gå? Hva skal vi gjøre nå?, Fagbokforlaget, Norway, pp. 129-151.

Zelime, J \& Deutschmann, M 2019, 'Communicating local knowledge in a foreign language - A comparative study of ideational and interpersonal aspects of primary school pupils' L1 and L2 texts in the Seychelles', L1-Educational Studies in Language and Literature, vol. 19, pp. 1-28.

Zelime, J, Deutschmann, M, \& Rijlaarsdam, G 2018, 'The effect of the language of testing on second language learners' academic performance in Social Studies: The case of Kreol Seselwa and English in the Seychelles classrooms', L1-Educational Studies in Language and Literature, vol. 18, pp. 1-22. 